\title{
Dynamic Integrated Model for Assessing Fisheries: Discard Bans as an Implicit Value-Added Tax
}

\author{
Jose Maria Da Rocha ${ }^{1}$ (D . Javier García-Cutrín ${ }^{1}$. Maria-Jose Gutiérrez ${ }^{2}$. \\ Raul Prellezo ${ }^{3}$. Eduardo Sanchez ${ }^{4}$
}

Accepted: 27 June 2021

(c) The Author(s) 2021

\begin{abstract}
Integrated economic models have become popular for assessing climate change. In this paper we show how these methods can be used to assess the impact of a discard ban in a fishery. We state that a discard ban can be understood as a confiscatory tax equivalent to a value-added tax. Under this framework, we show that a discard ban improves the sustainability of the fishery in the short run and increases economic welfare in the long run. In particular, we show that consumption, capital and wages show an initial decrease just after the implementation of the discard ban then recover after some periods to reach their steady-sate values, which are 16-20\% higher than the initial values, depending on the valuation of the landed discards. The discard ban also improves biological variables, increasing landings by $14 \%$ and reducing discards by $29 \%$ on the initial figures. These patterns highlight the two channels through which discard bans affect a fishery: the tax channel, which shows that the confiscation of landed discards reduces the incentive to invest in the fishery; and the productivity channel, which increases the abundance of the stock. Thus, during the first few years after the implementation of a discard ban, the negative effect from the tax channel dominates the positive effect from the productivity channel, because the stock needs time to recover. Once stock abundance improves, the productivity channel dominates the tax channel and the economic variables rise above their initial levels. Our results also show that a landed discards valorisation policy is optimal from the social welfare point of view provided that incentives to increase discards are not created.
\end{abstract}

Keywords Integranted económica models · DICE-RICE · Bayesian models · DYNARE · Discard ban $\cdot$ Age structured models

Mathematics Subject Classification 91B76 · 92D25

Authors thank to the participants at the 24th EAERE Conference in Manchester (United Kingdom) for their valuable comments. Da-Rocha, Garcia-Cutrin, Gutierrez and Sanchez acknowledge financial support from the Spanish Ministry of the Economy, Industry and Competitiveness (ECO2016-78819-R, AEI/FEDER, UE). Da-Rocha and Garcia-Cutrin also acknowledge financial support from Xunta de Galicia (ED431B 2019/34) and Gutierrez from the Basque Goverment (BiRTE, IT-1336-19). Funding for open access charge: Universidade de Vigo/CISUG.

Jose Maria Da Rocha

jmrocha@uvigo.es

Extended author information available on the last page of the article 
JEL Classification Q22 · Q28 · C61

\section{Introduction}

One fallout of fishery management is the bycatch problem, i.e., the unintended harvesting, discarding, and thus mortality of non-desired fish species. Discards in fishing are understood as the portion of a catch which is not retained on board during commercial fishing. Discarding is a historical characteristic of fisheries around the world. According to the FAO (Pérez Roda et al. 2019), discards per annum in global marine capture fisheries totalled 9.1 million tonnes (equivalent to $10.8 \%$ of the annual average catch) in 2010-2014. There are various reasons for discarding, including market (high grading) and regulatory reasons (quota exhaustion and minimum landing sizes).

In this situation, governments and fishery management authorities have implemented discards bans in various forms, areas, and ranges. In Europe, for example, Norway and Iceland have discard bans. In the European Union (EU) a landing obligation was introduced in the last EU Common Fisheries Policy (CFP) (EU 2013), along with the specific objective of achieving biomass levels capable of producing the Maximum Sustainable Yield (MSY) at individual stock level.

Academic and in particular scientific literature on fisheries economics has proposed the use of taxes as an optima way to control fisheries (Rosenman 1986). Using taxes to manage fisheries is thus not new at least at theoretical level; and nor is using taxes to reduce discards. For example, in New Zealand a "deemed value" system, i.e. a tax on over-quota catches, has been proposed. This tax is set with the main aim of discouraging discarding without creating incentives to target species not covered by quotas (Karp et al. 2019). Taxes are efficient when the economic benefit is intended to go wholly to the state (John 2002), but are sometimes considered to be politically unacceptable (Munro 1993) or not implementable due to the lack of the information required to define optimal tax levels and structures (Arnason 1991, 2000). If poorly designed, taxes can also create non-desired incentives, increasing the abundance of bycatch species and therefore increasing the probability of bycatch. This is the case when the tax is proportional to the bycatch and not to the bycatch/abundance ratio. (Squires et al. 2018).

This paper extends the bioeconomic literature on discards by analysing discard bans from a different perspective: instead of using taxes as an economic instrument to reduce discards, we seek to analyse a discard ban as an implicit value-added tax. The rationality of this proposal can be better understood from the perspective of the discard ban regulated under the EU landing obligation. This new regulation requires all catches of stocks subject to a total allowable catch regulation to be kept on board, landed and counted against quotas. This new regulation also states that fish under the legal minimum landing size can only be sold for fishmeal or other products not destined for direct human consumption. In practice, this can be understood as an obligation to fill vessels' tanks at least partially with unwanted catches that cannot be sold in the market at the same price as the wanted catches but that account towards the fishing quota. Under this regulation, landings can thus be classified as "good catches" (those that can be sold at regular prices) and "bad catches" (those associated with the discards that it is mandatory to land but whose sale is restricted). Filling up tanks with "bad catches" means less space for "good catches", so the new regulation acts as a confiscatory tax that confiscates "good catches" that would have been brought to port if the regulation was not in force. The logic behind this reasoning is illustrated in Fig. 1. 


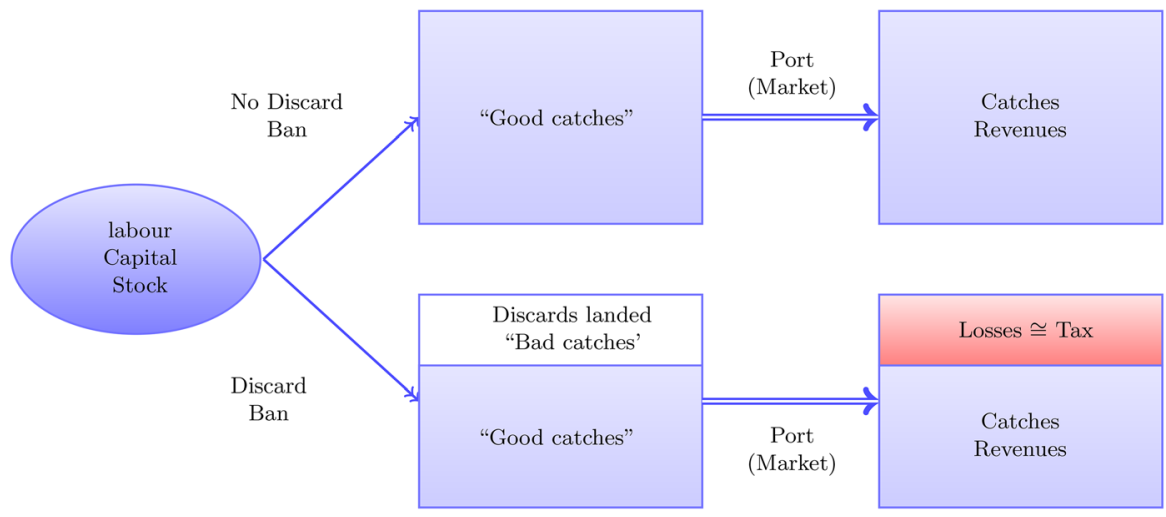

Fig. 1 The logic behind the interpretation of a discard ban as a confiscatory tax. Vessels use inputs (labour, capital and stock) to fill their tanks with catches. When the discard ban is in force, part of the tank is filled with "bad catches" (catches that cannot be sold at regular market prices). This means a loss that can be interpreted as a confiscation of the "good catches" (those that can be sold at regular market prices) that would have been brought to port if the regulation was not in force

Interpreting the discard ban as a confiscatory tax, enables the status quo (no discard ban and therefore zero tax) to be compared with an alternative situation where a discard ban that confiscates landed discards operates by setting an implicit tax such that the management objective is reached. Under this framework, the level of subsidies in the form of exemptions and a valuation of potential landed discards can be determined.

To that end, we build up a fisheries (macro) economic Dynamic Integrated Model. To the best of our knowledge, this is the first time that this methodology has been used to assess the effect of a discard ban. Dynamics Integrated models aggregate economic phenomena, building on explicit micro-foundations involving rational and forward looking optimising behaviour of individual economic agents (Kydland and Prescott 1982). This type of framework has been extensively used to assess macroeconomic policies and has recently become popular for assessing climate change. For example, the United States Environmental Protection Agency uses the Dynamic (or Regional) Integrated Climate Economy (DICE-RICE) framework by Nordhaus (2008, 2010) (see Ciarli and Savona (2019) for a complete review). More specifically, our integrated model shows four intrinsic characteristics: Dynamic (studying how the economy evolves over time), Stochastic (taking into account the fact that the economy is affected by dynamic random shocks), General (referring to the entire economy), and Equilibrium-based (subscribing to the Walrasian general equilibrium theory). Because of these characteristics, our macro-integrated model can be classified as a DSGE model.

Models of this kind have already been introduced into fisheries literature (Colla-DeRobertis et al. 2019; Da-Rocha et al. 2017). They are able to endogenously determine prices and fishing mortality and are easy to estimate (Colla-De-Robertis et al. 2019). Our contribution is to develop a DSGE model that enables the effects of discard ban to be assessed. The model is applied to the Spanish trawl fleet. This fleet is dependent on one species (the southern stock of hake) but also has discards of hake (small individuals) and other species. Given that the southern stock of hake is under a discard ban (EU landing obligation), it is important to assess how close to optimal (in terms of achieving MSY) the application of a discard ban is and whether there is room for valorising these discards. 


\section{Methods}

\subsection{Biological Model}

The biological model is a standard age-structured model. The stock evolves according to an age-structured population model where abundance, $N$, is given by

$$
N_{a+1, t+1}=e^{Z_{a, t}+\epsilon_{a, t+1}} N_{a, t},
$$

where $Z_{a, t}$ is the total mortality rate of age group $a$ in year $\mathrm{t}$ and $\epsilon_{a, t+1}$ represents an unexpected shock affecting the total mortality rate. The total mortality rate is decomposed into natural mortality, $m$, which is assumed, for the sake of simplicity, to be constant across ages and fishing mortality, $F_{t}$. Formally, $Z_{a, t}=-m-\left(p_{a}+d_{a}\right) F_{t}$, with $d_{a}$ and $p_{a}$ being the selectivity parameter of discards and landings for age $a$.

Given the stock dynamics, total discards and landings are defined, according to the Baranov catch function (Baranov 1918), as

$$
\begin{aligned}
\text { Discards }_{t} & =\sum_{a=1}^{C} \frac{\varpi_{a} d_{a} F_{t}}{m+\left(p_{a}+d_{a}\right) F_{t}}\left(N_{a, t}-N_{a+1, t+1}\right), \\
\text { Landings }_{t} & =\sum_{a=1}^{C} \frac{\varpi_{a} p_{a} F_{t}}{m+\left(p_{a}+d_{a}\right) F_{t}}\left(N_{a, t}-N_{a+1, t+1}\right),
\end{aligned}
$$

where $\varpi_{a}$ is the stock weight of age $a$ and $C$ is the total number of age-cohorts.

Finally, recruitment (in logarithm terms) is modeled as a 1-lag autoregressive process that can be expressed as

$$
\log N_{1, t+1}=(1-\rho) \log \bar{N}_{1}+\rho \log N_{1, t}+\epsilon_{1, t+1},
$$

where $\rho$ is the autocorrelation parameter, $\bar{N}_{1}$ is the mean recruitment and $\epsilon_{1, t+1}$ is an unobservable zero mean white noise.

\subsection{Household Preferences}

We define an economy made up of households that work and invest in a fishery. Roughly speaking, the household receives income in the form of a salary (as a worker) and capital rent (as a vessel owner). This income is used on consumer spending and to invest in future capital. In this context, any policy should be designed to optimize the flow of household welfare, which we assume depends positively on consumption and leisure time (and negatively on labour). More particularly, a representative household takes lifetime optimal decisions on consumption $(C)$, labour $(L)$ and capital investment $(I)$, with the factor prices, $r_{t}$ (for capital) and $w_{t}$ (for labour), being taken as given. Formally, at time $t$ the household faces the following inter-temporal decision problem:

$$
\max _{\left\{C_{t}, L_{t}, K_{t+1}\right\}_{t=0}^{\infty}} \mathbb{E}_{0} \sum_{t=0}^{\infty} e^{\epsilon_{\beta, t+1}} \beta^{t}\left\{\log C_{t}-L_{t}^{\varphi}\right\},
$$




$$
\begin{aligned}
\text { s.t } \quad C_{t}+I_{t} & =r_{t} K_{t}+w_{t} L_{t}, \\
K_{t+1} & =(1-\delta) K_{t}+I_{t},
\end{aligned}
$$

where $\mathbb{E}_{t}$ is the expectation given the information available at time $t, \beta$ is the discount factor, $K$ and $\delta$ represent the capital and its deprecation rate, respectively, and $\epsilon_{\beta, t+1}$ is a zero mean white noise that affects discounting which is unobservable in period $t$. Parameter $\varphi \geq 0$ represents the relative weight of leisure with respect to consumer spending in household welfare. $\varphi=0$ represents the case in which household welfare depends only on consumer spending. Note that in the first constraint of problem (1), $r_{t} K_{t}$ and $w_{t} L_{t}$ are the capital and labour income generated by the fishery activity which is allocated to consumption and investment. The second constraint of problem (1) represents the capital dynamics.

\subsection{Policy Constraints: Maximum Number of Days Per Vessel}

Fisheries managers do not directly control the fishing mortality that determines the amount of discards and landings, $F$. Rather, managers set the maximum number of days on which any vessel can fish, $\bar{L}$ (Da-Rocha and Gutiérrez 2012). However, this policy variable, $\bar{L}$, is affected by white noise implementation errors, $\epsilon_{\bar{L}}$. Formally, the maximum fishing days at any time $t$ are given by $\bar{L}_{t}=\bar{L} e^{\epsilon_{L, t+1} /(\varphi-1)}$. Note that the implementation error is dated at $t+1$ to reflect that it is known at that time and is therefore not available at time $t$ when households solve their optimization problem.

The household decision is constrained by the policy, introducing a non-convexity into the household objective function: households cannot choose the number of fishing days; they can only chose whether they form part of the crew and then they fish on all $\bar{L}$ days or not. To circumvent this problem, we follow Hansen (1985) and Rogerson (1988) and convexify the utility function by requiring households to choose lotteries rather than fishing days. In each period, households choose a probability of going fishing, $\pi_{t} \in(0,1)$, such that the expected utility of a household is given by

$$
\log C_{t}-\left[\pi_{t} \bar{L}_{t}^{\varphi}+\left(1-\pi_{t}\right) 0^{\varphi}\right]
$$

Under this framework of indivisible labour with lotteries, utility becomes linear in labour

$$
U\left(C_{t}, L_{t}\right)=\log C_{t}-e^{\epsilon_{\bar{L}, t+1}} B L_{t},
$$

where $L_{t}=\pi_{t} \bar{L}_{t}$ is the (expected) number of fishing days and $B=\bar{L}^{\varphi-1}$ represents the mean disutility of labour in each period.

\subsection{The Discard Ban as an Implicit Value-Added Tax}

Two regimes are defined in relation to the Discard Ban (DB). The first represents the economy before the DB implementation. The second represents the economy after the DB implementation in a given fishery. We refer to them as the pre- $D B$ and $D B$ regimes, respectively.

In the pre- $D B$ regime, unwanted catches are thrown back (discarded) instead of being landed in port. In this scenario the value-added generated by activity in the fishery comes exclusively from the value of landings. Formally, labour income, $w_{t} L_{t}$, plus capital income, $r_{t} K_{t}$, equals total income, $Y_{t}$, which coincides with the value of the landings. That is, 


$$
r_{t} K_{t}+w_{t} L_{t}=Y_{t}=p \times \text { Landings }_{t},
$$

where $p$ represents the price per tonne of fish landed.

In the $D B$ regime, discards cannot be thrown back but must be landed in port, where they can be sold under restrictions (they cannot follow the same commercial channel as "normal" landings). In this context, if discards had been thrown back the vessels' tanks could have been filled with "normal" landings that would be sold at regular price in the market. These potential revenues, which cannot be obtained due to the DB, can be understood as a confiscation of part of the value-added generated by the factor inputs (capital and labour). In economic costs terms the DB acts as a confiscatory tax on (part of) the "landed discards". Formally,

$$
r_{t} K_{t}+w_{t} L_{t}+\text { Taxes }_{t}=Y_{t}=p \times\left(\text { Landings }_{t}+\text { Discards }_{t}\right),
$$

where Taxes ${ }_{t}=\left(1-p_{d}\right) \times$ Discards $_{t}$ with $0 \leq p_{d} \leq 1$ being the proportion of "landed discards" that are not taxed. For the sake of simplicity, the price of landed fish is normalised here to 1 . This means that prices in the model are measured relative to 1. Figure 2 summarises the logic of the pre- $D B$ and $D B$ regimes.

With this formalisation $p_{d}$ can be interpreted as a policy variable that represents the degree of valuation allowed for "landed discards". $p_{d}=0$ would be a policy that bans the sale of "landed discards" under any circumstances. Their potential value is earmarked for taxes. At the other extreme, $p_{d}=1$ would be a $D B$ regime where "landed discards" are sold at the same price as "regular" landed fish and their value is used to pay for capital and labour inputs. Any value for $p_{d}$ between 0 and 1 implies that the sale of the "landed discards" is allowed, but through other commercial channels and therefore, at lower market prices than, landings.

An implicit value-added tax rate, $\tau$, is defined such that the collection is equivalent to the value of the discard taxed. This means that, Taxes $_{t}=\tau_{t} Y_{t}$, where

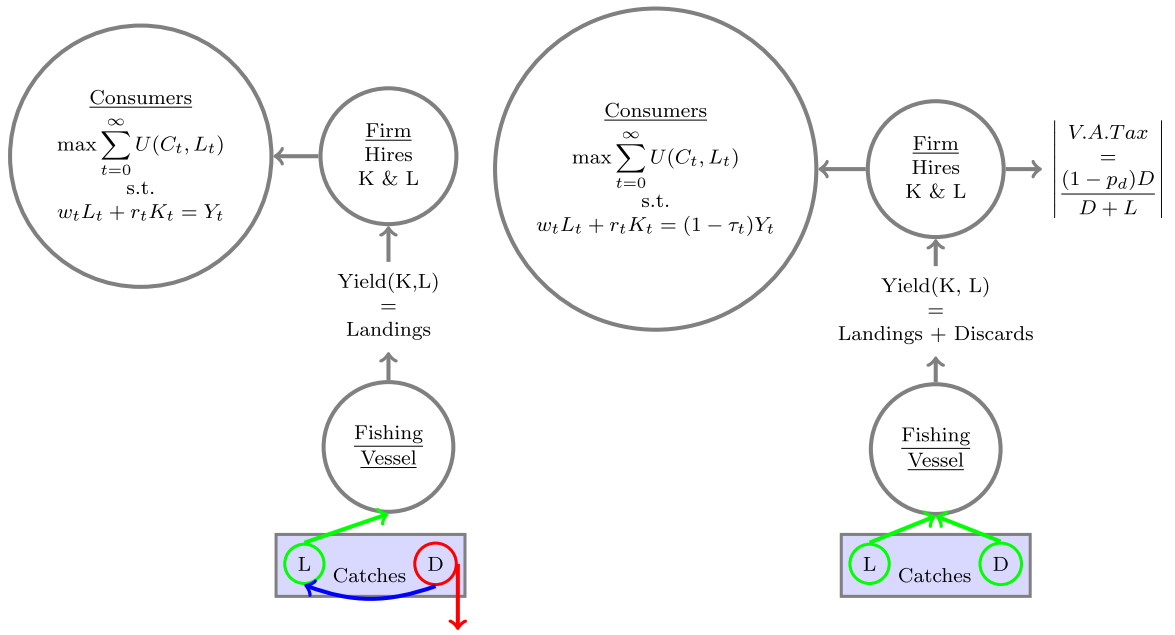

Fig. 2 The left panel represents the pre-DB regime where capital (K) and labour (L) are used to produce only landings. Discards are thrown back rather than being landed in port. The right panel represents the $D B$ regime, where capital $(\mathrm{K})$ and labour $(\mathrm{L})$ are used to produce landings and also discards. Discards can be sold in part and the implicit value of the unsold part acts as a confiscatory tax 


$$
\begin{aligned}
\tau_{t} & =\frac{\text { Taxes }_{t}}{Y_{t}}=\frac{\left(1-p_{d}\right) \times \text { Discards }_{t}}{\text { Landings }_{t}+\text { Discards }_{t}} \\
& =\frac{\left(1-p_{d}\right) \sum_{a=1}^{E} \frac{w_{a} d_{a} F_{t}}{\left[m+\left(p_{a}+d_{a}\right)\right] F_{t}}\left(N_{a, t}-N_{a+1, t+1}\right)}{\sum_{a=1}^{E} \frac{w_{a}\left(p_{a}+d_{a}\right) F_{t}}{\left[m+\left(p_{a}+d_{a}\right)\right] F_{t}}\left(N_{a, t}-N_{a+1, t+1}\right)} .
\end{aligned}
$$

\subsection{Integrating Capital and Labour Income with Discard Ban}

The economic impact of the DB is assessed by comparing the endogenous (expected) paths of wages, $\left\{w_{t}\right\}_{t=0}^{\infty}$, and rental prices, $\left\{r_{t+1}\right\}_{t=0}^{\infty}$, in pre- $D B$ and $D B$ regimes. The key-stone for computing these variables is the use of a value-added production function that integrates capital and labour income with the value of the landings generated in each scenario.

When capital and labour income shares are quasi constant over time, a (macro) Cobb Douglas aggregate production function can be considered a good proxy for this value-added production function (Cobb and Douglas 1928). Gollin (2002) shows that the shares of national income accruing to capital and labour appear to be fairly constant over long periods of time. In fisheries, the lack of data makes it difficult to calculate capital and labour shares; most income is in the form of mixed rents from self-employment. However, Guillen et al. (2017) states that "(in) most fisheries worldwide, crew are paid through different shared remuneration systems rather than a fixed wage”. In this sense, a Cobb-Douglas production function, $Y_{t}=A_{t} K_{t}^{\alpha} L_{t}^{1-\alpha}$, where $A$ is the total factor productivity (TFP) and $\alpha$ and $1-\alpha$ are the income shares devoted to capital and labour, respectively, is a good instrument for representing this situation. In general terms, the TFP represents the portion of the output from the economy that cannot be explained by the use of the explicit inputs (capital and labour, in this case). In the context of fisheries, TFP measures mainly the impact on the production of other inputs such as resource abundance (biomass) or technological developments.

We reproduce these stylised facts by assuming that the aggregate value of landings is obtained in competitive input markets. Formally, firms share out the income from landings between $K$ and $L$ by maximising net income:

$$
\begin{gathered}
\max _{L_{t}, K_{t}} \mathbb{E}_{t}\left\{\left(1-\tau_{t}\right) Y_{t}-w_{t} L_{t}-r_{t} K_{t}\right\}, \\
\text { s.t. } Y_{t} \leq A_{t} K_{t}^{\alpha} L_{t}^{1-\alpha} .
\end{gathered}
$$

Therefore, firms use the value of landings after taxes only to pay capital and for the income factor. From the first order conditions of the optimization problem (2), the following emerges:

$$
\begin{aligned}
w_{t} L_{t} & =\left(1-\tau_{t}\right)(1-\alpha) Y_{t} \equiv & & \text { Labour income } \\
r_{t} K_{t} & =\left(1-\tau_{t}\right) \alpha Y_{t} \equiv & & \text { Capital income }
\end{aligned}
$$

Note that national income identity is satisfied at any time $t$ :

Capital income $\mathrm{t}_{\mathrm{t}}+$ Labour income $_{\mathrm{t}}+$ Taxes $_{\mathrm{t}} \equiv Y_{t}=$ value of Landings $_{\mathrm{t}}+$ value of Discards . $_{\text {. }}$ 
The model is closed, relating the TFP of the value-added production function $\left(A_{t}\right)$ to the abundance of the fishery (biomass). This approach has been followed to assess the effects of global warming in fisheries (Da-Rocha et al. 2014), the economic impact of the CFP (Colla-De-Robertis et al. 2019) and stock-rebuilding policies (Da-Rocha et al. 2017). In particular, we consider that the TFP is endogenously determined by the stock according to

$$
A_{t}=e^{\epsilon_{A, t+1}}\left(\sum_{a=1}^{E} w_{a} N_{a, t}\right)^{\alpha_{\text {stock }}},
$$

where $\alpha_{\text {stock }}$ is the TFP elasticity and $\epsilon_{A, t+1}$ represents TFP shocks due to factors other than those affecting stock abundance. Note that $\alpha_{\text {stock }}$ can also be interpreted as the stock productivity, i.e. it measures how much productivity changes, in percentage terms, when the biomass increases by $1 \%$.

\subsection{The Complete Integrated Model}

All the above structures build up a DSGE model which is able jointly to determine the economic and biological variables that characterize the fishery. Formally: given the initial population structure, $\left(N_{1,0}, N_{2,0}, \ldots, N_{7,0}\right)$, the initial capital stock, $K_{0}$, and the policy implemented by fishery managers, $\left(L\right.$ and $\left.p_{d}\right)$, a dynamic equilibrium is defined as the sequence of $\left\{C_{t}, L_{t}, K_{t+1}, I_{t}, Y_{t}, w_{t}, r_{t}, A_{t}, \tau_{t}, F_{t}, \text { Landings }_{t} \text {, Discards }{ }_{t}, N_{1, t+1}, N_{2, t+1}, \ldots, N_{E, t+1}\right\}_{t=0}^{\infty}$, that solves the following set of equations:

$$
\begin{gathered}
C_{t}=\frac{w_{t}}{e^{\epsilon_{\bar{L}, t+1} B}}, \\
\frac{1}{\beta}=\mathbb{E}_{t}\left[e^{\epsilon_{\beta, t+1}} \frac{C_{t}}{C_{t+1}}\left(1-\delta+r_{t+1}\right)\right], \\
C_{t}+I_{t}=w_{t} L_{t}+r_{t} K_{t}, \\
K_{t+1}=(1-\delta) K_{t}+I_{t}, \\
w_{t}=\left(1-\tau_{t}\right)(1-\alpha) A_{t} K_{t}^{\alpha} L_{t}^{-\alpha}, \\
r_{t}=\left(1-\tau_{t}\right) \alpha A_{t} K_{t}^{\alpha-1} L_{t}^{1-\alpha}, \\
\text { Landings }_{t}=\sum_{a=1}^{C} \frac{\varpi_{a} p_{a} F_{t}}{m+\left(d_{a}+p_{a}\right) F_{t}}\left(N_{a, t}-N_{a+1, t+1}\right), \\
\text { Discards } K_{t}^{\alpha} L_{t}^{1-\alpha}, \\
\sum_{a=1}^{C} \frac{\varpi_{a} d_{a} F_{t}}{m+\left(d_{a}+p_{a}\right) F_{t}}\left(N_{a, t}-N_{a+1, t+1}\right),
\end{gathered}
$$




$$
\begin{gathered}
Y_{t}=\text { Discards }_{t}+\text { Landings }_{t}, \\
\log N_{1, t+1}=\rho \log N_{1, t}+\epsilon_{1, t+1}, \\
\log N_{a+1, t+1}=-m-\left(d_{a}+p_{a}\right) F_{t}+\log N_{a, t}+\epsilon_{a, t+1}, \\
A_{t}=e^{\epsilon_{A, t+1}}\left(\sum_{a=1}^{C} \varpi_{a} N_{a, t}\right)^{\alpha_{\text {stock }}}, \\
\tau_{t}=\frac{\left(1-p_{d}\right) \text { Discards }_{t}}{Y_{t}} .
\end{gathered}
$$

This system of equations comprises $12+C$ independent equations (note that equation holds $\forall 1 \leq a<C-1)$. Therefore, $12+C$ endogenous variables must be found, for the initial conditions given. The equilibrium implied by Eqs. (3)-(16) summarises the behaviour of households and firms and the economic and biological balances that determine prices and fishing mortality. Firstly, households take decisions on consumer spending, labour (fishing days) and investment taking input prices ( $w$ and $r$ ) as given. Equations (3)-(6), which come from the first order conditions and the restrictions of the optimization problem solved by households (problem (1)), reflect these decisions. Secondly, firms share the net income after taxes from landings, to remunerate labour and capital. Equations (7)-(9) come from the first order conditions and the restriction of the problem solved by firms (problem (2)). Thirdly, total yield comes from fishing operations accounting for landings and "landed discards" according to the Baranov catch functions that both relate to fishing mortality. Equations (10)-(14) determine the fishing mortality, abundance, discards and landings generated by labour and investment decisions. Fourthly, Eq. (15) connects the TFP of the value-added production function used to split income between inputs (capital and labour) with the abundance of the fishery (biomass). Finally, Eq. (16) defines the confiscatory tax on the "landed discards".

From the practical point of view, the DSGE model proposed can be estimated and simulated using Dynare software under the Matlab framework, although it can also run on GNU Octave (a free clone of Matlab). Dynare is free open-source software developed mainly by researchers from CEPREMAP (France) who maintain a public platform hosted at https:// www.dynare.org (Adjemian et al. 2011). Dynare is able to handle a wide range of economic models, in particular DSGE models. It is able to perform simulations of the model given a calibration of the model parameters and is also able to estimate those parameters given a dataset. Roughly speaking, the researcher writes a text file containing the list of model variables, the dynamic equations linking them together, the computing tasks to be performed and the desired graphical or numerical outputs. A useful resource for macro-modelling starters can be found in Madeira (2013). We provide the codes used for the estimation and simulations of our DSGE model as supplementary material. 


\section{Case Study}

The model proposed is generic and can be applied to assess policy issues in fisheries management. In particular, we illustrate how to apply the methodology to assess the implementation of a DB in the Galician trawl fleet (north-west of Spain). This fleet operates in the EU Iberian Atlantic waters, bordering to the north-east on the Spanish-French border and to the south-west on the Straits of Gibraltar. The fleet is highly dependent on hake (Merluccius merluccius) and in particular on the EU southern stock (ICES Divisions 8c and 9a) of hake (Sampedro et al. 2017).

The EU southern stock of hake has been managed under various management strategies. In 2005 a recovery plan for this stock was set with controlled TACs in order to recover the spawning stock of biomass (EC Reg. 2166/2005; EC 2005). This recovery plan has been assessed under different frameworks (e.g. Da-Rocha et al. 2010) and is no longer considered appropriate (ICES 2017). Other plans for this stock have sought to regulate (limit) the maximum number of days at sea per vessel so as to reduce fishing mortality (EU 2017). Currently, this stock is under the EU landing obligation, the economic consequences of which are studied in Villasante et al. (2016a, b)

The methodological strategy consists of two steps. First, the stock productivity, $\alpha_{\text {stock }}$, is estimated by Bayesian methods in the benchmark model without taxes (i.e. the pre$D B$ regime) using historical data. Second, the estimated stock productivity parameter, $\alpha_{\text {stock }}$, is used to simulate the impact of DB implementation in the form of a confiscatory tax (DB regime) considering different discard valuation policies.

Yearly observations from 2004 to 2015 of 11 variables are used to estimate the model: abundance for seven ages $\left(N_{1}, N_{2}, \ldots N_{7}\right)$, fishing mortality $(F)$, catches $(Y)$, fishing days $(L)$, and capital $(\mathrm{K})$. The biological population data and technological (Baranov) parameters, $\left(m_{a}, p_{a}, d_{a}, \varpi_{a}\right)$ are taken from ICES (2017). Table 1 summarises the parameters of the age-structured model used. The data are available as supplementary material. The factor share, $\alpha$, is set to $1 / 3$ following Gollin (2002) and capital depreciation, $\delta$, is set at $12.90 \%$ to match fixed capital allowances from Spanish national statistics for the fishing fleet (MAPAMA 2016). Labour disutility, $B$, is set to 5.5954 and the discount factor, $\beta$, to 0.9637 (equivalent to a $3.7 \%$ discount rate) to match the 2015 labour level and a capital-output ratio of 2 (Madsen et al. 2012).

Table 1 The EU southern stock of hake (age parameters). Source: ICES (2017)

\begin{tabular}{llllll}
\hline Age & \multicolumn{2}{l}{ Natural } & & \multicolumn{2}{l}{ Fishing mortality } \\
\cline { 2 - 3 } \cline { 5 - 6 } & Mortality & Weight & & Landings & Discards \\
& $m_{a}$ & $\varpi_{a}$ & & $p_{a}$ & $d_{a}$ \\
\hline 1 & 0.40 & 0.02 & & 0.01 & 0.04 \\
2 & 0.40 & 0.16 & & 0.19 & 0.17 \\
3 & 0.40 & 0.48 & 0.57 & 0.09 \\
4 & 0.40 & 1.07 & 0.65 & 0.04 \\
5 & 0.40 & 1.95 & 0.65 & 0.01 \\
6 & 0.40 & 3.01 & 0.65 & 0.01 \\
7 & 0.40 & 4.20 & 0.65 & 0.01 \\
\hline
\end{tabular}




\section{Results}

\subsection{Bayesian Estimation of the Stock Productivity Parameter}

The stock productivity parameter, $\alpha_{\text {stock}}$, is estimated from time series data that represent the period in which there was no obligation to land discards in port. This is equivalent to estimating the benchmark model represented by the system of Eqs (3)-(16) for the pre-DB regime, in which the "landed discards" are zero (and therefore, the confiscatory tax is also zero).

The calibration of the model keeps some parameters fixed and estimates those related to the model dynamics using Bayesian techniques. In particular, fixed parameters are maintained for the value-added production function (factor shares, $\alpha$ ), the investment function (depreciation of physical capital, $\delta$ ) and the parameters from the Baranov catch equation $\left(w_{a}, p_{a}\right.$ and $\left.m\right) .12$ parameters are estimated, including those related to $(i)$ the dynamics of the stock productivity (elasticity, $\alpha_{\text {stock }}$, and standard deviation of $\epsilon_{A, t}$ ); (ii) recruitment and abundance dynamics (recruitment persistence, $\rho$, and the standard deviation of abundance dynamics shocks, $\epsilon_{a, t}$ for ages 1-7); (iii) policy dynamics (standard deviation of $\epsilon_{\bar{L}}$ ); and, (iv) discounting (standard deviations of $\epsilon_{\beta, t}$ ).

The Bayesian estimation involves combining the estimation of the parameters by maximum likelihood using the observed data set with the information obtained from prior distributions defined for the same parameters. The standard practice in the estimation of DSGE models is followed in selecting the prior distributions. In particular, we assume Inverse Gamma prior distributions for non-negative parameters (such as the standard deviations of the shock processes) and prior normal distributions for the elasticity of the stock productivity.

Table 2 summarises the priors and the posterior of the estimated parameters. Comparing the posterior estimates with the priors is informative. Figure 3 shows the prior and posterior distributions of the estimated variables. The posterior distributions estimated (the black line, with the vertical green line representing the posterior modal value) depart

Table 2 Bayesian estimation of the model (Pre-DB regime)

\begin{tabular}{lllllll}
\hline Parameters & Prior mean & Post. mean & $90 \% \mathrm{HPD}$ interval & & Prior dist. & pstvar \\
\hline$\alpha_{\text {stock }}$ (stock productivity) & 0.355 & 0.3485 & 0.3484 & 0.3485 & Norm & 0.0100 \\
$\rho$ (recruitment persistence) & 0.010 & 0.4749 & 0.2883 & 0.6097 & invg & Inf \\
Standard deviation of shocks & Prior mean & Post. mean & $90 \% \mathrm{HPD}$ interval & & Prior & pstdev \\
$\epsilon_{\bar{L}}$ (policy) & 0.010 & 0.3193 & 0.2201 & 0.4299 & invg & Inf \\
$\epsilon_{\beta}$ (rental capital) & 0.010 & 0.0063 & 0.0024 & 0.0114 & invg & Inf \\
$\epsilon_{A}$ (TFP) & 0.010 & 0.3107 & 0.2071 & 0.4025 & invg & Inf \\
$\epsilon_{1}$ (mortality age 1) & 0.010 & 0.1880 & 0.1681 & 0.2078 & invg & Inf \\
$\epsilon_{2}$ (mortality age 2) & 0.010 & 0.0516 & 0.0317 & 0.0647 & invg & Inf \\
$\epsilon_{3}$ (mortality age 3) & 0.010 & 0.3429 & 0.2158 & 0.4412 & invg & Inf \\
$\epsilon_{4}$ (mortality age 4) & 0.010 & 0.2218 & 0.1525 & 0.2993 & invg & Inf \\
$\epsilon_{5}$ (mortality age 5) & 0.010 & 0.1513 & 0.0903 & 0.2070 & invg & Inf \\
$\epsilon_{6}$ (mortality age 6) & 0.010 & 0.1132 & 0.0687 & 0.1592 & invg & Inf \\
$\epsilon_{7}$ (mortality age 7) & 0.010 & 0.0808 & 0.0551 & 0.1153 & invg & Inf \\
\hline
\end{tabular}

invg, inverse gamma distribution; norm, normal distribution; pstvar, posterior variance 

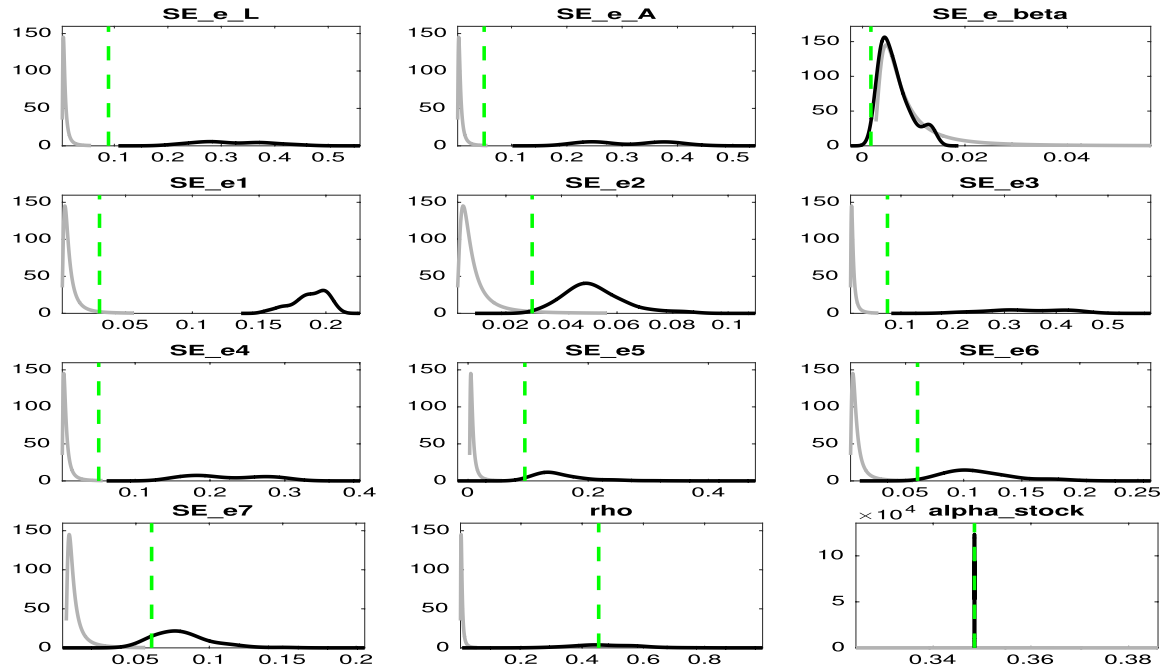

Fig. 3 Priors and posteriors. The black (grey) line represents the posterior (prior), the vertical greenline represents the posterior mode value distribution of the standard deviations of the policy shock, $\epsilon_{\bar{L}}$, productivityshock, $\epsilon_{A}$, discounting shock, $\epsilon_{\beta}$, biological shocks affecting ages $\left\{\epsilon_{a}\right\}_{a=1}^{7}$, and of the recruitmentpersistence, $\rho$ and stock productivity $\alpha_{\text {stock}}$.

substantially from the prior distributions assumed (grey line). In particular, the prior and posteriors for recruitment persistence $(\rho)$ and the policy shock $\left(\epsilon_{\bar{L}}^{-}\right)$differ substantially, indicating that the information content of the aggregated data is very informative. By contrast the prior and posterior distributions of stock productivity $\left(\alpha_{\text {stock }}\right)$ are quite similar. This is because we used a recursive selection process to find the prior.

It is noteworthy that the estimated value for stock productivity $(0.35)$ is quite similar to the elasticity of the physical capital (1/3 following Gollin (2002)). This means that in this fishery a $1 \%$ increase in physical capital has the same impact on yield as a $1 \%$ increase in biomass.

To assess the model's overall goodness of fit, we compare the evolution of the data used in the estimation process to that predicted by the model for the same variables. Figure 4 makes a comparison, displaying the evolution of the series used (the "real" time series) with that generated by the model for the same variables. The results of the real versus model-based projections reassure us the model represents the behaviour of the fishery.

\subsection{Impact of the DB}

To assess the impact of the DB, the Bayesian distribution estimates of the parameters $\left(\alpha_{\text {stock }}\right.$ and $\rho$ ) and shocks affecting the fishery, $\left\{\epsilon_{L, t}^{-}, \epsilon_{\beta_{t}}, \epsilon_{1, t}, \epsilon_{2, t}, \ldots \epsilon_{7, t}\right\}_{t=0}^{\infty}$, under the pre-DB regime (see Table 2), are used to simulate the model under the $D B$ regime. This impact is assessed considering two different discard valuation policy scenarios: $i$ ) a zero-valuation policy, simulated assuming that all the discards landed are confiscated (i.e. $p_{d}=0$ in Eq. (16)); and ii) a minimal-valuation policy in which only a proportion of the discards landed are confiscated (i.e. $0<p_{d}<1$ in Eq. (16)). 

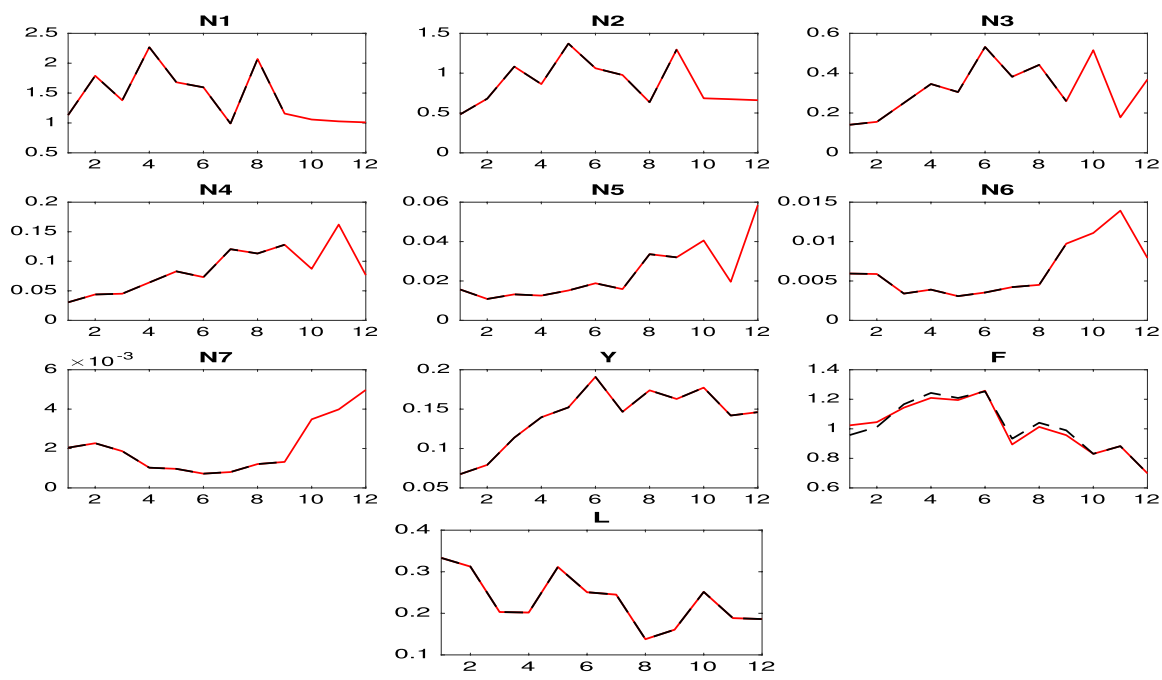

Fig. 4 Historical and smoothed variables. The data set used includes yearly observations (2004-2015) of abundance for 7 ages $\left(N_{1}, N_{2}, N_{3}, N_{4}, N_{5}, N_{6}, N_{7}\right)$, catches $(Y)$, fishing mortality $(F)$ and fishing days $(L)$. Abundances are normalised using the median of recruits. The black line represents the "true" time series and the red line the estimated one

The zero-valuation policy represents the extreme policy case in which no discards can be sold at a positive price for any use. The minimal-valuation policy could reflect a situation where landed discards can be sold for fishmeal or other by-products not destined for direct human consumption. It could also reflect cases where some exemptions to the DB are granted as a percentage of total landings. To give a number to this valuation, we use $p_{d}=0.10$, which corresponds to the minimal exemption of $5 \%$ discards from obligatory landing if they were sold at 0.2 euro (10\% of discards are valued at regular price and $90 \%$ are confiscated).

\subsubsection{Long-Run Impact of the DB}

Before any comparison between regimes is made, it is necessary to understand the long term situation of this fishery. The fishery itself is managed under the CFP, which means that the management target is the MSY. In particular we assume that the target is a $F_{m s y}$ of hake, which is approximated by the $F_{\text {max }}$. That target must therefore be computed and it must be assessed how far the projections of our proposed model are from it.

Table 3 shows the mean long-run steady-state values for the biological variables of the fishery under different regimes. The first three columns represent the steady-state solution of the system of Eqs. (3)-(16) when it is simulated under the pre-DB regime (first column), the $D B$ regime with minimal-valuation discard policy (second column) and the $D B$ regime with a zero-valuation discard policy (third column). The fourth column represents the steady-state solution when the fishery management target, MSY, is taken into account. Technically, this solution comes from the maximization of landings instead of the social welfare, and the discount factor is taken as 1 (Da-Rocha et al. 2012). The steady-state values implied by an MSY management-based policy are observed to be very close to those 
Table 3 Where is the MSY?

\begin{tabular}{lllll}
\hline & Pre-DB & \multicolumn{2}{l}{ Discard valuation } & \multirow{2}{*}{ MSY } \\
\cline { 3 - 4 } & & Minimum & Zero & \\
\hline $\mathrm{F}$ & 1.104 & 0.578 & 0.569 & $0.591 \sim F_{\max }$ \\
$\mathrm{N} 1$ & 1.000 & 1.000 & 1.000 & 1.000 \\
$\mathrm{~N} 2$ & 0.634 & 0.651 & 0.652 & 0.651 \\
$\mathrm{~N} 3$ & 0.286 & 0.354 & 0.356 & 0.353 \\
$\mathrm{~N} 4$ & 0.092 & 0.162 & 0.164 & 0.160 \\
$\mathrm{~N} 5$ & 0.029 & 0.073 & 0.074 & 0.071 \\
N6 & 0.009 & 0.033 & 0.034 & 0.032 \\
N7 & 0.003 & 0.015 & 0.016 & 0.015 \\
Landings & 0.150 & 0.173 & 0.173 & 0.173 \\
Discards & 0.025 & 0.018 & 0.018 & 0.018 \\
A (productivity) & 0.161 & 0.915 & 0.918 & 0.910 \\
\hline
\end{tabular}

obtained from the proposed model. In this sense, our fisheries DSGE model can be considered a useful tool for fisheries managers.

Table 4 focuses on the results generated from the proposed DSGE model for assessing the impact of the DB in the long-run. It shows the mean and the standard deviation for all

Table 4 Long-run impact of a discard ban (simulated moments)

\begin{tabular}{|c|c|c|c|c|c|c|}
\hline & \multirow{2}{*}{\multicolumn{2}{|c|}{ Pre-DB Regime }} & \multicolumn{4}{|c|}{ DB regime } \\
\hline & & & \multicolumn{2}{|c|}{$\begin{array}{l}\text { Zero-valuation } \\
\left(p_{d}=0\right)\end{array}$} & \multicolumn{2}{|c|}{$\begin{array}{l}\text { Min-valuation } \\
\left(p_{d}=0.10\right)\end{array}$} \\
\hline & Mean & SD & Mean & SD & Mean & $\mathrm{SD}$ \\
\hline $\mathrm{Y}$ & 0.1504 & 0.0552 & 0.1903 & 0.0458 & 0.1906 & 0.0451 \\
\hline $\mathrm{C}$ & 0.1116 & 0.0298 & 0.1280 & 0.0180 & 0.1300 & 0.0181 \\
\hline I & 0.0388 & 0.0297 & 0.0445 & 0.0308 & 0.0452 & 0.0301 \\
\hline K & 0.3008 & 0.1155 & 0.3451 & 0.0844 & 0.3504 & 0.0842 \\
\hline $\mathrm{L}$ & 0.1606 & 0.0249 & 0.1606 & 0.0253 & 0.1606 & 0.0243 \\
\hline w & 0.6244 & 0.1669 & 0.7164 & 0.1009 & 0.7275 & 0.1014 \\
\hline$r$ & 0.1667 & 0.0395 & 0.1667 & 0.0319 & 0.1667 & 0.0309 \\
\hline A & 0.7598 & 0.1479 & 0.9185 & 0.0927 & 0.9149 & 0.0923 \\
\hline $\mathrm{F}$ & 1.1044 & 0.5315 & 0.5694 & 0.0885 & 0.5784 & 0.0882 \\
\hline N1 & 1.0000 & 0.2136 & 1.0000 & 0.2136 & 1.0000 & 0.2136 \\
\hline $\mathrm{N} 2$ & 0.6343 & 0.1464 & 0.6515 & 0.1446 & 0.6512 & 0.1445 \\
\hline N3 & 0.2857 & 0.1437 & 0.3558 & 0.1497 & 0.3545 & 0.1491 \\
\hline N4 & 0.0924 & 0.0771 & 0.1638 & 0.0846 & 0.1622 & 0.0837 \\
\hline N5 & 0.0289 & 0.0341 & 0.0741 & 0.0425 & 0.0729 & 0.0419 \\
\hline N6 & 0.0093 & 0.0140 & 0.0341 & 0.0206 & 0.0334 & 0.0203 \\
\hline N7 & 0.0030 & 0.0054 & 0.0157 & 0.0098 & 0.0153 & 0.0095 \\
\hline Discards & 0.0252 & 0.0037 & 0.0184 & 0.0022 & 0.0178 & 0.0021 \\
\hline Landings & 0.1504 & 0.0552 & 0.1726 & 0.0424 & 0.1726 & 0.0445 \\
\hline Tax rate & & & 0.0933 & 0.0178 & 0.0805 & 0.0154 \\
\hline
\end{tabular}


the variables (economic and biological) in the long term under the two discard valuation policies considered. The first point to highlight is that the implementation of the DB suggests an implicit value-added tax of $9 \%$ with zero-valuation for landed discards and $8 \%$ for minimal-valuation.

Our results show that the DB has positive long-run effects on fisheries in two aspects. First, comparing the means of the pre- $D B$ regime steady state with those from the $D B$ regime, substantial increases emerge in the main economic indicators (landings, consumption, investment, capital, wages and productivity). There is also an improvement in the stock status, with significant decreases in fishing mortality and discards. Moreover, these positive results appear under the two "landed discards" valuation policies considered. Second, the implementation of the DB would lead to a substantial reduction in fluctuations in both economic and biological variables.

DB does not affect the number of fishing days selected by fleets in the long term. This result was expected. When the maximum number of days is set to manage the fishery, the optimal decision of households is to fish the maximum number of days allowed. This decision does not depend on the stock productivity or the particular DB in place, or even on whether there is a DB or not.

The use of a Cobb-Douglas valued added function enables the steady state capital/ labour ratio to be expressed as:

$$
\frac{K}{L}=[(1-\tau) A \alpha \hat{\beta}]^{\frac{1}{1-\alpha}}, \quad A=\left(\sum_{a=1}^{7} w_{a} N_{a, t}\right)^{\alpha_{\text {stock }}},
$$

where $\hat{\beta}=\beta[1-\beta(1-\delta)]^{-1}$ is a constant. This expression shows the two channels through which the DB affects the capitalization of a fishery:

On the one hand there is the tax channel which reflects that confiscating the "landed discards" associated with the DB reduces the incentive to invest in the fishery. This negative effect is embodied in the term $(1-\tau)^{\frac{1}{1-\alpha}}$ and represents a $14.1 \%$ reduction when the pre-DB regime is compared with the $D B$ regime under a zero-valuation discard policy.

On the other hand there is the productivity channel. Through this channel, the DB increases the abundance of the stock, improving the productivity of the fishery and, therefore, the incentives to invest. This positive effect is reflected in the term $A^{\frac{1}{1-\alpha}}$ and represents a $30.6 \%$ increase when the pre- $D B$ regime is compared with the $D B$ regime under a zerovaluations discard policy.

The net effect of the DB on capital is positive and represents a $16.5 \%$ increase. Since the DB does not affect the number of fishing days, this increase in capitalization implies more powerful vessels fishing the same number of fishing days.

The impact of the DB on input prices is concentrated on wages, given that the rental price does not depend on the policy. More specifically, $r=1 / \hat{\beta}$, which depends exclusively on exogenous parameters such as the discount factor and the capital depreciation rate.

Wages are affected by the DB through the same two channels as capital. In the steady state, wages can be expressed as

$$
w=(1-\alpha)\left[(1-\tau) A\left(\frac{\alpha}{\hat{\beta}}\right)^{\alpha}\right]^{\frac{1}{1-\alpha}} .
$$

The positive effect of the $\mathrm{DB}$ on productivity dominates the negative effect of taxing landed discards leading to a $16.5 \%$ net increase in wages (as in capital). 
The type of discard valuation policy used in implementing of the DB is the key variable in assessing its impact from the welfare viewpoint. Table 4 shows that consumer spending is at its highest when the DB allows for the minimal valuation considered for the sale of landed discards. Since the number of fishing days is not affected by the discard ban, any change in the welfare of households comes exclusively from changes in consumer spending. It can therefore be concluded that a change in the DB policy that gives a value to landed discards would improve the welfare of society, provided that incentives for new discards are not created.

\subsubsection{Short-Run Impact: Transition}

It is important to analyse what effects he DB has during the transition to the steady-state solution. To that end, we simulate the evolution of all variables from an initial situation representing the pre- $D B$ regimen to the steady state implied by the pre-DB regime under different discard valuation policies.

Figure 5 summarises the transitional impact for the cases of zero and minimal discard valuation policies. As mentioned above, the steady-state value of the number of fishing days and the rental prices in the steady-state do not depend on the DB. This is reflected in the simulations since the long-term value of both variables coincides with the initial
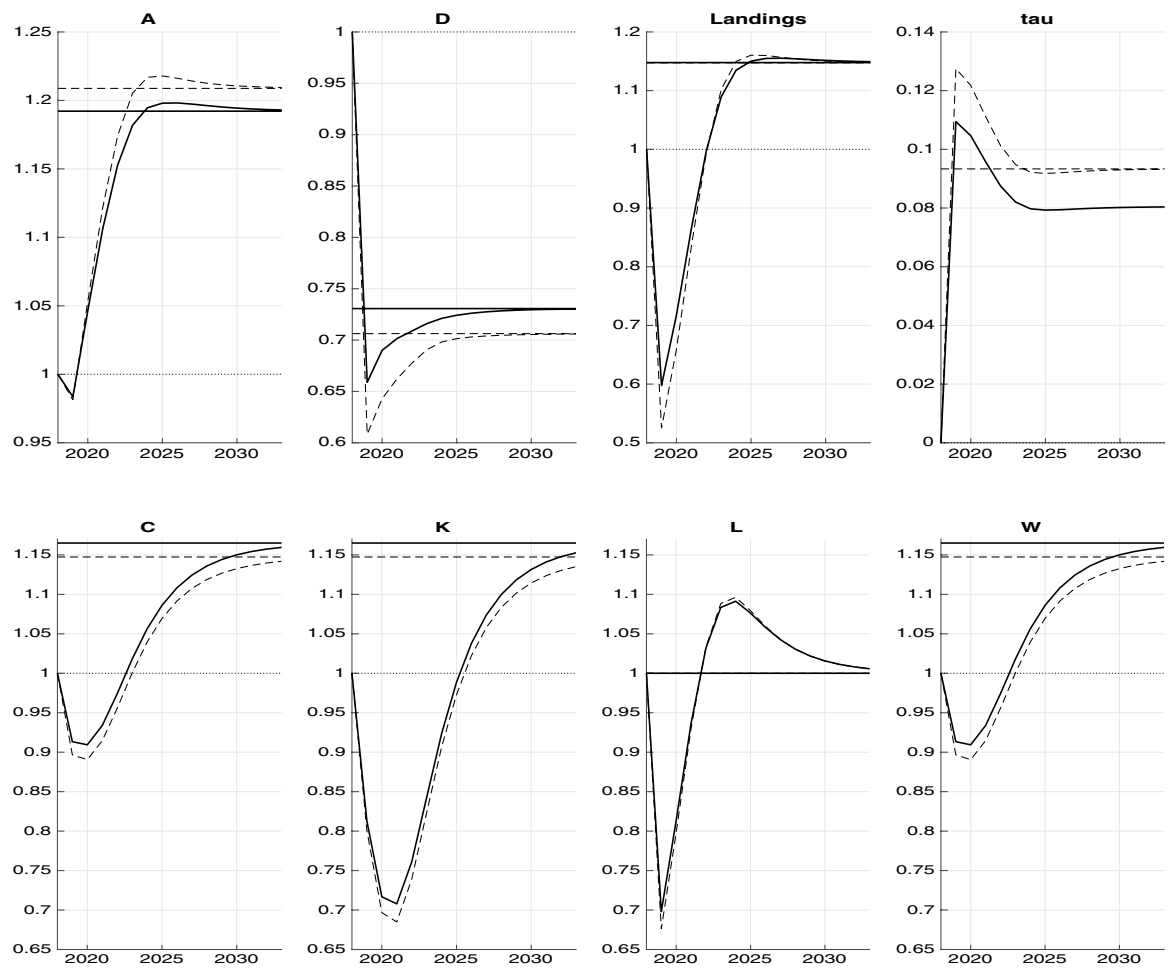

Fig. 5 The initial situation represents the pre-DB regimen normalised to 1 . The solid line shows the evolution of the variable assuming minimal-valuation for discards, i.e. 5\% of the "landed discards" are exempt and can be sold to a price of 0.2 euro ( $10 \%$ of regular price). The dashed line shows the evolution of the variable assuming zero-valuing for discards 
situation. The rest of the economic variables increase in the long term but show very different patterns. Consumer spending, capital and wages, show an initial decrease and then recover to reach their steady-state values, which are $16-20 \%$ higher than the initial value, depending on the discard valuation policy implemented. These patterns reflect the fact that in the first few years the negative effect from the tax channel dominates the positive effect from the productivity channel because the stock needs some time to recover. Once stock abundance improves, the productivity channel dominates the tax channel, bringing the economic variables up to above the initial level.

Simulations also reflect how the fishery improves from the biological viewpoint with the implementation of the DB. In the long term, landings increase by $14 \%$ while discards decrease by $29 \%$ with respect to the pre-DB regime. However, in the short term both variables show significant drops. More specifically, landings decrease by around $50 \%$ and discards by $40 \%$ in the first year of DB application.

\section{Conclusions}

We show that the application of a DB can be interpreted as a confiscatory tax on the value-added created by a fishery. In particular we show that there are two channels through which the DB affects the fishery with opposite signs. The first one, the tax chan$n e l$, consists of the value-added confiscated and not returned to households. The second, the productivity channel, increases abundance and is related to the policy objective. In the long term the productivity channel dominates the tax channel and therefore society is better off under a DB, especially if some valorisation of landed discards is allowed.

In the short term the tax channel dominates and society is worse off, given that all the positive efficiency gains come from stock recovery, which requires time. Therefore, consumption, capital and wages decrease in the initial periods but then recover to their steady-state values, which are $16-20 \%$ higher than their initial values. It is also concluded that any change in the DB policy that gives a value to landed discards (albeit lower one than normal landings) would improve the welfare of society.

Our results are consistent with the previous literature. In particular, they are consistent with Villasante et al. (2016a), who estimate that the impact of the EU landing obligation on the Galician fleet could represent a yield loss in the range of $10-15 \%$ for the initial periods. This range is compatible with the reduction of $14.1 \%$ estimated in this study when only the tax channel is considered. We show that if a DB is considered as an implicit tax losses will appear in the short-run because of the tax channel domination. However, we also show that there is an additional productivity channel which helps achieve management objectives, and that in the long term it outweighs the short-term losses. From the management viewpoint, the policy of valorising landed discards could be used as a way of promoting the use more selective fishing gears within the Galician fleets, which in the end will also boost the productivity channel.

Note that in this study we consider full implementation of a DB, i.e. that the DB regime is implemented by the fleet. This might not actually be the case, given that there are other moral hazard problems arising from the unobservability of catches and discards by society (Jensen and Vestergaard 2002) and therefore related to control and enforcement issues in regard to this policy. 
We conclude that a DB is good in the long term because it acts as an implicit valueadded tax and thus helps achieve management objectives, though in the short term its impact will be negative.

Funding Open Access funding provided thanks to the CRUE-CSIC agreement with Springer Nature.

Open Access This article is licensed under a Creative Commons Attribution 4.0 International License, which permits use, sharing, adaptation, distribution and reproduction in any medium or format, as long as you give appropriate credit to the original author(s) and the source, provide a link to the Creative Commons licence, and indicate if changes were made. The images or other third party material in this article are included in the article's Creative Commons licence, unless indicated otherwise in a credit line to the material. If material is not included in the article's Creative Commons licence and your intended use is not permitted by statutory regulation or exceeds the permitted use, you will need to obtain permission directly from the copyright holder. To view a copy of this licence, visit http://creativecommons.org/licenses/by/4.0/.

\section{References}

Adjemian S, Bastani H, Juillard M, Karamé F, Maih J, Mihoubi F, Perendia G, Pfeifer J, Ratto M, Villemot S (2011) Dynare: reference manual, version 4. Dynare working papers. CEPREMAP 1

Arnason R (1991) Efficient management of ocean fisheries. Eur Econ Rev 35(2-3), 408-417

Arnason R (2000) Economic instruments for achieving ecosystem objectives in fisheries management. ICES J Marine Sci 57(3), 742-751

Baranov F (1918) On the question of the biological basis of fisheries. Inst Sci Ichthyol Invest Proc 1(1), $81-128$

Ciarli T, Savona M (2019) Modelling the evolution of economic structure and climate change: a review. Ecol Econ 158, 51-64

Cobb C, Douglas P (1928) A theory of production. Am Econ Rev 18:139-165

Colla-De-Robertis E, Da Rocha JM, García-Cutrín J, Gutiérrez MJ, Prellezo R (2019) A bayesian estimation of the economic effects of the Common Fisheries Policy on the Galician Fleet: a dynamic stochastic general equilibrium approach. Ocean Coast Manag 167:137-144

Da-Rocha JM, Cerviño S, Gutiérrez MJ (2010) An endogenous bio-economic optimization algorithm to evaluate recovery plans: an application to southern hake. ICES J Mar Sci 67(9), 1957-1962

Da-Rocha JM, Gutiérrez MJ (2012) Endogenous fishery management in a stochastic model: why do fishery agencies use TACs along with fishing periods? Environ Resour Econ 53(1), 25-59

Da-Rocha JM, Gutiérrez MJ, Cerviño S (2012) Reference points based on dynamic optimization: a versatile algorithm for mixed-fishery management with bio-economic age-structured models. ICES J Mar Sci 69(4), 660-669

Da-Rocha JM, Gutiérrez MJ, Villasante S (2014) Economic effects of global warming under stock growth uncertainty: the European sardine fishery. Region Environ Change 14(1), 195-205. doi: 10.1007/ s10113-013-0466-y

Da-Rocha JM, Prellezo R, Sempere J, Taboada Antelo L (2017) A dynamic economic equilibrium model for the economic assessment of the fishery stock-rebuilding policies. Mar Policy 81:185-195

EC (2005) Council Regulation No 2166/2005 of 20 December 2005 establishing measures for the recovery of the Southern hake and Norway lobster stocks in the Cantabrian Sea and Western Iberian peninsula and amending Regulation (EC) No. 850/98 for the conservation of fishery resources through technical measures for the protection of juveniles of marine organisms. Off J Eur Union 345:5-10

EU (2013) Regulation (EU) no 1380/2013 of the European Parliament and of the Council of 11 December 2013 on the common fisheries policy, amending council regulations (ec) no 1954/2003 and (ec) no 1224/2009 and repealing council regulations (EC) no 2371/2002 and (EC) No 639/2004 and council decision $2004 / 585 / \mathrm{ec}$

EU (2017) Council regulation (EU) no 2017/127 of 20 January 2017 fixing for 2017 the fishing opportunities for certain fish stocks and groups of fish stocks, applicable in union waters and, for union fishing vessels, in certain non-union waters. Off J Eur Union

Gollin D (2002) Getting income shares right. J Polit Econ 110(2), 458-474 
Guillen J, Boncoeur J, Carvalho N, Frangoudes K, Guyader O, Macher C, Maynou F (2017) Remuneration systems used in the fishing sector and their consequences on crew wages and labor rent creation. Marit Stud 16(1):3

Hansen G (1985) Indivisible labor and the business cycle. J Monet Econ 16(3), 309-327

ICES (2017) ICES Advice on fishing opportunities, catch, and effort Greater Northern Sea, Celtic Seas, and Bay of Biscay and Iberian Coast ecoregionsPublished 30 June 2017. https://doi.org/10.17895/ices.pub. 3134

ICES (2017) Report of the Working Group for the Bay of Biscay and Iberian waters Ecoregion (WGBIE)411 May 2017, ICES Headquarters, Copenhagen, Denmark. ICES CM/ACOM:12. 534

Jensen F, Vestergaard N (2002) Moral hazard problems in fisheries regulation: the case of illegal landings and discard. Resour Energy Econ 24(4), 281-299

John P (2002) Input and output controls: the practice of fishing effort and catch management in responsible fisheries. FAO, p 75

Karp WA, Breen M, Borges L, Fitzpatrick M, Kennelly SJ, Kolding J, Nielsen KN, Viaarsson JR, Cocas L, Leadbitter D (2019) Strategies used throughout the world to manage fisheries discards - lessons for implementation of the eu landing obligation. In: Uhlmann SS, Ulrich C, Kennelly SJ (eds) The European landing obligation: reducing discards in complex, multi-species and multi-jurisdictional fisheries. Springer, Cham, pp 3-26

Kydland F, Prescott E (1982) Time to build and aggregate fluctuations. Econometrica 50(6), 1345-70

Madeira J (2013) Simulation and estimation of macroeconomic models in dynare. In: Hashimzade N, Thornton MA (eds) Handbook of research methods and applications in empirical macroeconomics. Edward Elgar, Cheltenham, pp 593-606

Madsen JB, Mishra V, Smyth R (2012) Is the output-capital ratio constant in the very long run?*. Manchester School 80 (2), 210-236. doi: 10.1111/j.1467-9957.2010.02222.x

MAPAMA (2016) Ministerio de Agricultura, Pesca y Alimentación. Estadísticas pesqueras: Indicadores económicos del sector pesquero. Macromagnitudes pesqueras

Munro GR (1993) Issues in fisheries management under the new law of the sea. UBC, Discussion Paper no. 93-20

Nordhaus W (2008) A question of balance weighing the options on global warming policies. https://www. scopus.com/inward/record.uri?eid=2-s2.0-84902738959\&partnerID=40\&md5=a0808cc1de2aa51 3dd029b21b89a4ff5

Nordhaus W (2010) Economic aspects of global warming in a post-copenhagen environment. Proc Natl Acad Sci USA 107 (26), 11721-11726

Pérez Roda MA, Gilman E, Huntington T, Kennelly SJ, Suuronen P, Chaloupka M, Medley PA (2019) A third assessment of global marine fisheries discards. Tech. Rep. 633. FAO, Rome

Rogerson R (1988) Indivisible labor, lotteries and equilibrium. J Monet Econ 21(1), 3-16

Rosenman RE (1986) The optimal tax for maximum economic yield: fishery regulation under rational expectations. J Environ Econ Manag 13(4), 348-362

Sampedro P, Prellezo R, García D, Da-Rocha JM, Cerviño S, Torralba J, Touza J, García-Cutrín J, Gutiérrez MJ (2017) To shape or to be shaped: engaging stakeholders in fishery management advice. ICES J Mar Sci 74(2), 487-498

Squires D, Restrepo V, Garcia S, Dutton P (2018) Fisheries bycatch reduction within the least-cost biodiversity mitigation hierarchy: conservatory offsets with an application to sea turtles. Mar Policy 93:55-61

Villasante S, Pierce G, Pita C, Guimerans C, Garcia Rodrigues J, Antelo M, Da Rocha J, Cutrin J, Hastie L, Veiga P, Sumaila U, Coll M (2016a) Fishers' perceptions about the eu discards policy and its economic impact on small-scale fisheries in galicia (north west spain). Ecol Econ 130:130-138

Villasante S, Pita C, Pierce G, Guimerans C, Rodrigues J, Antelo M, Rocha J, Cutrin J, Hastie L, Sumaila U, Coll M (2016b) To land or not to land: how do stakeholders perceive the zero discard policy in european small-scale fisheries? Mar. Policy 71:166-174

Publisher's Note Springer Nature remains neutral with regard to jurisdictional claims in published maps and institutional affiliations. 


\section{Authors and Affiliations}

\section{Jose Maria Da Rocha ${ }^{1}$ (D) Javier García-Cutrín ${ }^{1}$ - Maria-Jose Gutiérrez ${ }^{2}$.} Raul Prellezo ${ }^{3}$. Eduardo Sanchez ${ }^{4}$

Javier García-Cutrín

fjgarcia@uvigo.es

Maria-Jose Gutiérrez

mariajose.gutierrez@ehu.eus

Raul Prellezo

rprellezo@azti.es

Eduardo Sanchez

edusanchez@uvigo.es

1 ECOBAS, Universidade de Vigo, 36310 Vigo, Spain

2 Dpto Análisis Económico and BIRTE, University of the Basque Country (UIPV/EHU), Avd Lehendakari Aguirre 83, 48015 Bilbao, Spain

3 AZTI, Txatxarramendi Ugartea z/g, 48395 Sukarrieta, Bizkaia, Spain

4 Dpto de Economía Cuantitativa, Universidade de Santiago de Compostela, Baixada Burgo das Nacions s/n, 15782 Santiago de Compostela, Spain 